\title{
Geological Carbon Sequestration: A New Approach for Near-Surface Assurance Monitoring
}

\section{Lucian Wielopolski}

Environmental Science Department, Brookhaven National Laboratory, Bldg. 490, Upton, NY 11973, USA; E-Mail: 1wielo@bnl.gov; Tel.: +1-631-344-3656

Received: 24 December 2010; in revised form: 23 February 2011 / Accepted: 8 March 2011 /

Published: 11 March 2011

\begin{abstract}
There are two distinct objectives in monitoring geological carbon sequestration (GCS): Deep monitoring of the reservoir's integrity and plume movement and near-surface monitoring (NSM) to ensure public health and the safety of the environment. However, the minimum detection limits of the current instrumentation for NSM is too high for detecting weak signals that are embedded in the background levels of the natural variations, and the data obtained represents point measurements in space and time. A new approach for NSM, based on gamma-ray spectroscopy induced by inelastic neutron scatterings (INS), offers novel and unique characteristics providing the following: (1) High sensitivity with a reducible error of measurement and detection limits, and, (2) temporal- and spatial-integration of carbon in soil that results from underground $\mathrm{CO}_{2}$ seepage. Preliminary field results validated this approach showing carbon suppression of $14 \%$ in the first year and $7 \%$ in the second year. In addition the temporal behavior of the error propagation is presented and it is shown that for a signal at the level of the minimum detection level the error asymptotically approaches $47 \%$.
\end{abstract}

Keywords: carbon; monitoring; geological sequestration; spectroscopy; neutrons; gamma-rays; errors; minimum detectable limits

\section{Introduction}

Global warming and climate change are attributed to increases in the concentration of greenhouse gases (GHG) in the atmosphere, from anthropogenic emissions of $\mathrm{CO}_{2}$, from the pre-industrial revolution level of about $260 \mathrm{ppm}$, to present day concentrations of about $391 \mathrm{ppm}$, viz., $\sim 35 \%$ 
increase [1]. The main sources of GHG emissions are associated with burning fossil fuels, changing land usage, and cultivation of the soil. To combat global climate change will require a combination of approaches including improving energy efficiency and using alternative energy sources. Predictions of the increased use of energy globally during this century and continued reliance on fossil fuels point to a further rise in $\mathrm{GHG}$ emissions [2] with a concomitant one in atmospheric $\mathrm{CO}_{2}$ concentrations. These consequences cannot be abated unless major changes are made in the way energy is produced and used; in particular, how carbon is managed [3,4]. Mitigating the forecast increase in fossil-fuel consumption includes producing clean fuels, capturing industrially generated $\mathrm{CO}_{2}$, and sequestering this $\mathrm{CO}_{2}$ in deep geologic formations (carbon capture \& sequestration (CCS)). The attractiveness of the CCS program stimulated significant investments by governments and the private sector to develop the necessary technologies, and to evaluate whether $\mathrm{CO}_{2}$ control could be implemented safely and effectively to maintain the $\mathrm{CO}_{2}$ in reservoirs. The United States Department of Energy (USDOE) prepared a roadmap for the CCS program [5]. The program's early planners recognized the potential risks of geological storage to humans and ecosystems that might arise from leaking injection wells, abandoned wells, across faults, and from ineffective confining layers. Hence, cost-effective, robust monitoring must be an integral part of and specifically designed for every individual CCS project.

Monitoring the status and the fate of $\mathrm{CO}_{2}$ plume from geological carbon sequestration (GCS) projects is mandatory as stipulated by the Environmental Protection Agency's (EPA's) permitting processes for underground injections [6-9]. The monitoring generally falls into two types; monitoring deep reservoirs to confirm their stability and integrity, and, monitoring above the reservoir, i.e., near-surface monitoring (NSM) of water, air, and soil to assure public health and environmental safety. The IPCC and the USDA reports outline these two domains, differing in their objectives and the instrumentation required for monitoring [10,11], as depicted schematically in Figure 1. In general, the IPCC guidelines [10] stipulate a 99\% reservoir-retention capacity over a 1,000 year period. That, for a $200 \mathrm{Mt} \mathrm{CO}_{2}$ reservoir, translates into a yearly acceptable leak of 2,000 t/year or $\sim 5.5 \mathrm{t} /$ day. Considering the surface area of a reservoir through which a gas could leak, its tortuous passage and dispersion on its movement from a depth of several thousand feet to the surface, we would expect very low fluxes of $\mathrm{CO}_{2}$ to be evident at the surface. The exceptions might be leaks occurring near injection- and abandoned-wells, or known geological faults. Many of the well-established techniques of monitoring $\mathrm{CO}_{2}$ in the atmosphere and in the near-surface areas were adopted directly for assessing leaks from geological carbon-sequestration sites in spite of their inadequate sensitivities and point measurements in space and time. Table 2 of the USDOE's report summarizes their basic characteristics and the challenges they pose for detecting low-level signals [11]. Thus, current instrumentation faces a double challenge of reducing the minimum detectable limit (MDL) with minimum detectable change (MDC), and distinguishing real changes from natural ones due to seasonal- and diurnal-variations in the field $\mathrm{CO}_{2}$ fluxes. Point measurements might well be inadequate when the location of the leak is unknown, so that it probably is necessary to couple them with line- and area-integrated $\mathrm{CO}_{2}$ measurements, or design sensor networks to cover the area $[12,13]$. 
Figure 1. Scheme of two monitoring regions: One, near the surface for assurance monitoring; and, two, deep monitoring for evaluating the reservoir's integrity.

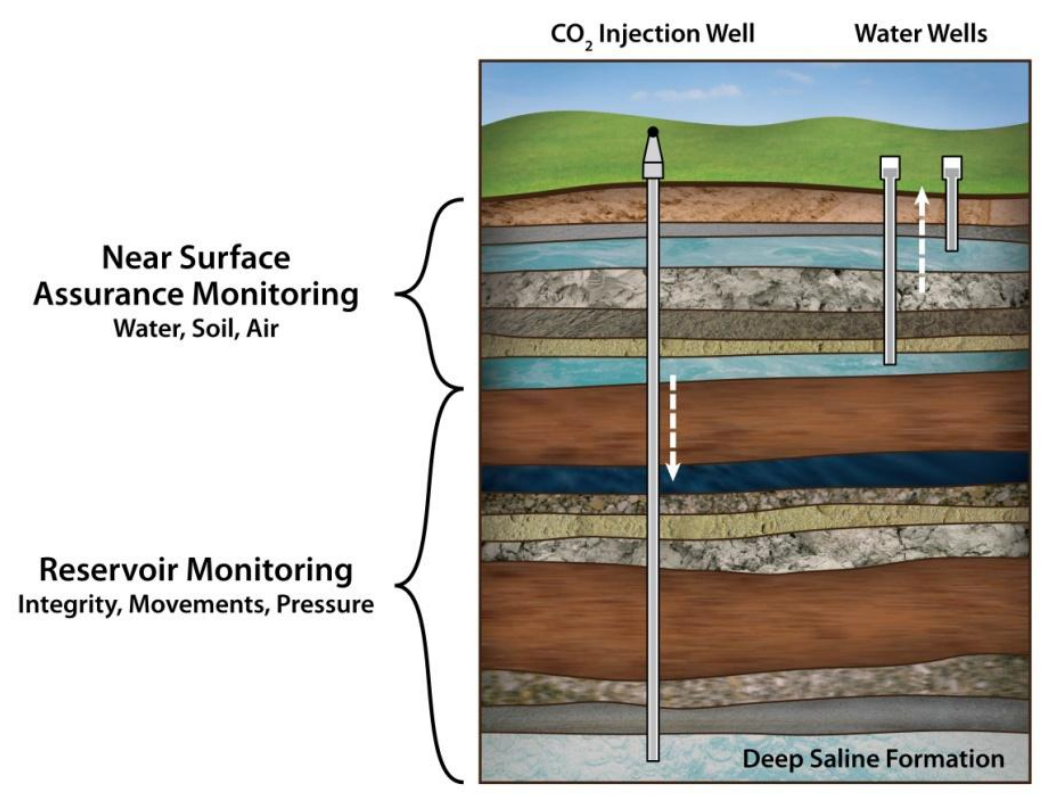

To address the hurdles of the MDL, field natural variability and point measurements, a new approach that, rather than directly measuring the fluxes of seeping $\mathrm{CO}_{2}$, measures a secondary quantity, namely total carbon in soil (TOC). Since the soil's $\mathrm{CO}_{2}$ levels affect its $\mathrm{pH}$ and the activity of the plants' roots it contains, they influence the TOC levels. Hence, a slow $\mathrm{CO}_{2}$ seepage will increase cumulatively the soil $\mathrm{CO}_{2}$ content inversely impacting TOC. Lower noise and reduced natural variability surrounding the TOC, lowering the MDL levels is enabled. Measurements of TOC offer a temporal- and spatial-integration of the impact of prolonged low seepage of $\mathrm{CO}_{2}$. Time integration is accomplished by measuring the cumulative effect on the TOC of prolonged exposure to changes in soil $\mathrm{CO}_{2}$ [14]; Wielopolski and Mitra earlier reported such a decrease in TOC [15]. Others detailed the overall degradation of vegetation caused by $\mathrm{CO}_{2}$ leaks from underground $\mathrm{CO}_{2}$ springs in Mammoth Mountain, California, and in Latera caldera, Italy [16,17]. This paper emphasizes the benefits of the error reduction of the proposed new system and of using unique scanning capacity of the inelastic neutron scattering (INS) system for spatially integrated monitoring. Thus, the hypothesis tested is that a $\mathrm{CO}_{2}$ leak would impact the vegetation and result in a near surface carbon suppression; like in the vicinity of natural $\mathrm{CO}_{2}$ vents; and the objectives are to demonstrate the validity of the hypothesis and suitability of the INS to measure these changes. INS system is briefly described and the reduction in the error propagation and lowering of the MDL and MDC are outlined. Theoretically, both can be reduced to reasonably low levels.

\section{Site and Setup}

\subsection{Site}

The applicability of INS for monitoring GCS was demonstrated at the zero emission research and technology (ZERT) facility located on a former agricultural plot at the western edge of the Montana 
State University-Bozeman campus, Bozeman, Montana, USA. This facility was established for testing and tuning instrumentation for studying near-surface $\mathrm{CO}_{2}$ transport and detection under controlled conditions. The site, located at an elevation of $1,495 \mathrm{~m}$, is covered with vegetation consisting primarily of alfalfa (Medicago sativa), yellow blossom sweet clover (Meliotus officinalis), dandelion (Taraxacum officinale, Canada thistle (Cirdium arvense), and a variety of grasses (family Poaceae). The field is typical of the Bozeman area, with alluvial sandy gravel deposits overlain by a few meters of silts and clays with a blanket of topsoil. There are two distinct soil horizons; a topsoil, some 0.2 to $1.2 \mathrm{~m}$ thick, of organic silt, clay, and some sand, and an underlying deposit of sandy gravel extending down to about $5 \mathrm{~m}$. Carbon-dioxide was introduced through a $100 \mathrm{~m}$ long horizontal well installed between 1 and $2.5 \mathrm{~m}$ deep, and injected at a rate of 0.3 tons per day for twenty eight days; Spangler et al., give more detailed information on the site and injection system [18,19]. Figure 2 shows the site with the $\mathrm{CO}_{2}$ storage tank, and the transport line to a control hut that regulates and monitors the flow through the horizontal well. The hot spots indicate regions of high $\mathrm{CO}_{2}$ flow that degraded the vegetation.

Figure 2. Site of the ZERT facility showing: a $\mathrm{CO}_{2}$ storage tank, a flow control hat, and the location of the horizontal well. It also shows the measurement sites over a hot spot and the background region.

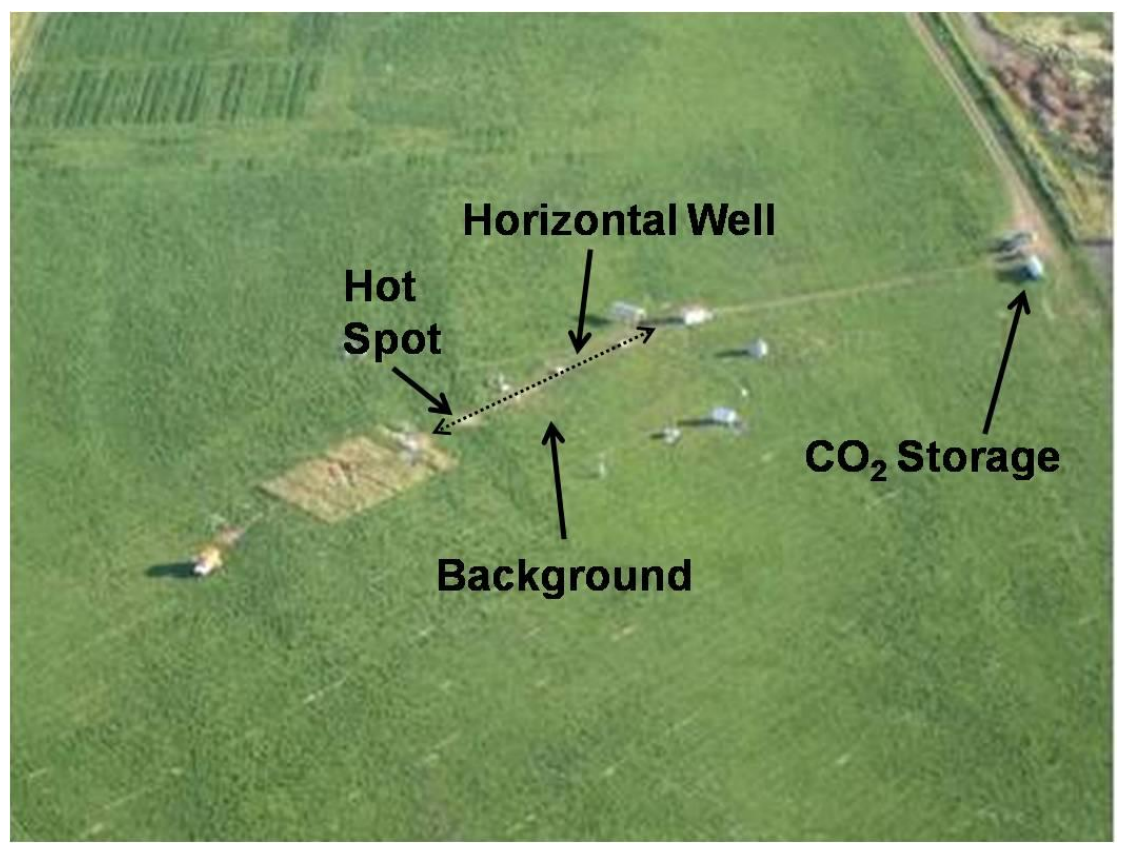

\subsection{INS System}

The INS method is based on spectroscopy of gamma rays induced by fast (14 MeV) neutrons interacting with the elements present in soil via inelastic neutron scattering and thermal neutron capture processes. The INS system consists of a neutron generator (NG) that is turned off at the end of the data acquisition, detection and spectroscopy systems, and a power supply, all of which are mounted on a cart about $30 \mathrm{~cm}$ above the ground, thus enabling use in stationary or scanning modes of operation. Analysis and calibration of the characteristic elemental gamma-ray spectra resulting from inelastic neutron scatterings and thermal neutron captures (Figure 3) provide quantitative information 
on elemental concentrations in soil. The INS system interrogates large soil volume of about $0.3 \mathrm{~m}^{3}$ to an effective depth of $\sim 30 \mathrm{~cm}$, as detailed by Wielopolski et al. [15,20]. The linear correlation between INS signal counts and carbon concentration was demonstrated in synthetic soils [21] and in natural fields using soil chemical analysis [22,23]. Thus, the net number of counts in the carbon peak can be

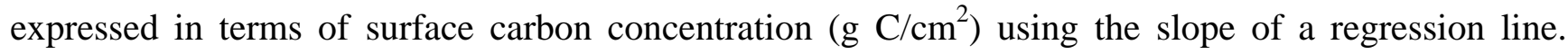
Similarly, INS system's signal resulting from scanning capabilities, a key feature for spatial averaging, is converted to carbon content using the same calibration line. This is pertinent for detecting low level signals over large areas where the actual location of the leak is unknown. Uniquely, the error and MDL in the INS system can be lowered by extending the counting time or increasing the system's sensitivity, i.e., by increasing the number of detectors. These features are demonstrated in the following section on spectral analysis.

The soil carbon measurements at the ZERT facility were taken by placing the INS system above a "hot spot", marked in Figure 2 that was impacted by $\mathrm{CO}_{2}$ leakage from the horizontal well. These measurements were compared with those taken away from the horizontal well.

Figure 3. Typical gamma-ray spectra induced by inelastic neutron scattering and thermal neutron capture reactions.
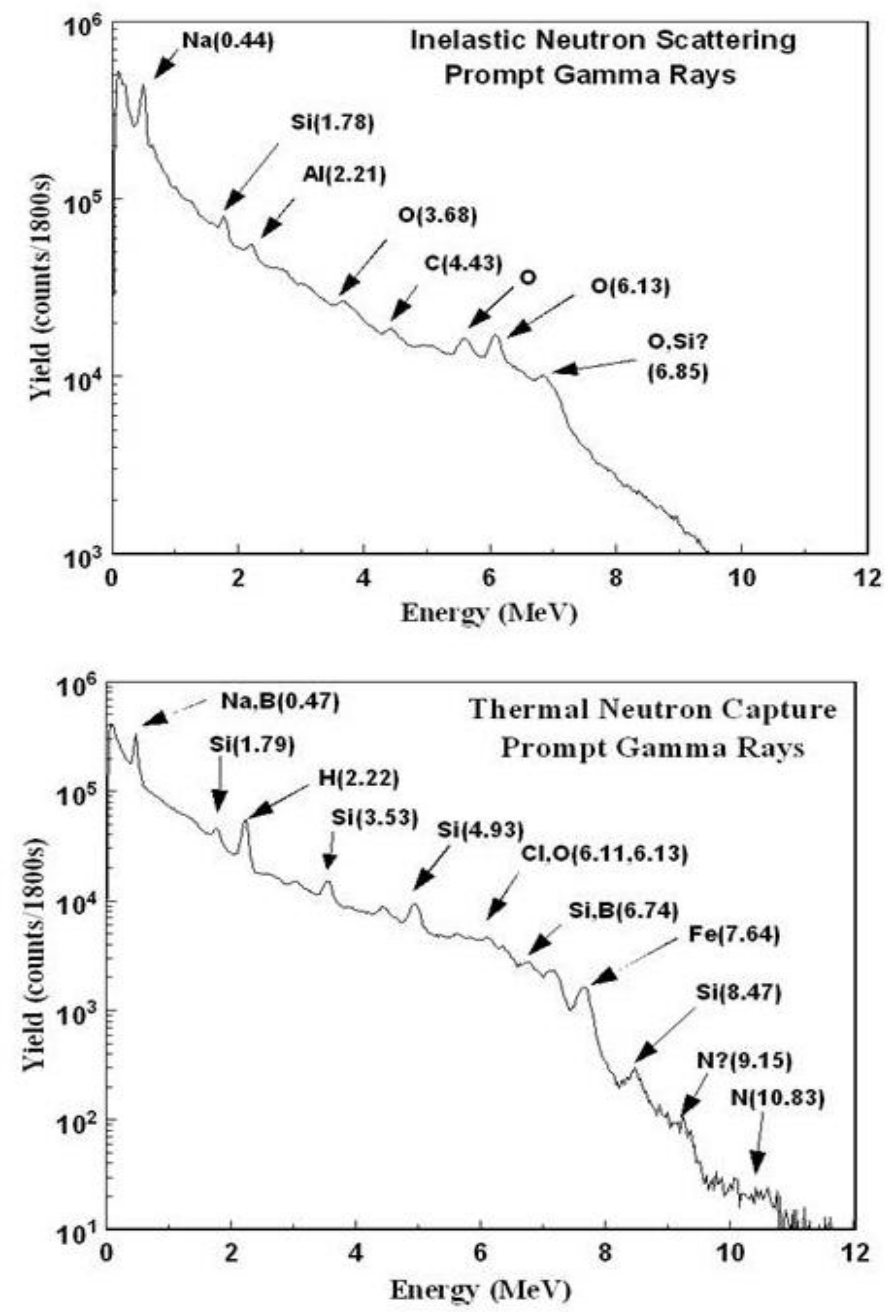


\section{Spectral Analysis}

Statistics of nuclear counting follows a binomial distribution, which for a large number of counts $\mathrm{N}>12$ can be approximated by a normal distribution with a mean value, $\mathrm{N}$, and standard deviation (SD) the square-root of $\mathrm{N}(\operatorname{sqrt}(\mathrm{N}))$ [24]. By extension, in nuclear spectroscopy, the gamma-ray events in the detector are represented by the number of counts falling into contiguous energy intervals (channels). Figure 4 depicts a partial spectrum with expanded energy intervals where interest lies with the number of counts in the energy interval 'ab' embracing a carbon peak. The total number of counts in that energy interval $\mathrm{T}_{\mathrm{t}}$ following $\mathrm{T}$ minutes of counting time is due to unknown incident signal counting rate $S_{r}$ times $T$, and the background counting rate $B_{r}$ times $T$. Thus, $T_{t}=S_{r} T+B_{r} T$ in which $\mathrm{B}_{\mathrm{r}} \mathrm{T}$ is the area of a trapezoid 'abcd' marked in Figure 4. Conversely, the net number of counts associated with an element (E) of interest, $S_{r} T$, is given by the difference $T_{t}-B_{r} T$. The INS's net counts are converted to conventional units of areal density $\left(\mathrm{g} \mathrm{E} / \mathrm{m}^{2}\right)$ by dividing the net signal by the sensitivity of the system, $\mathrm{s}$, defined as the number of counts acquired during a counting period $\mathrm{T}, \mathrm{S}_{\mathrm{r}} \mathrm{T}$, per gram element per unit area; $\mathrm{k}$ is proportionality constant with matching units of $\mathrm{g} \mathrm{E} / \mathrm{m}^{2}$. Thus $\mathrm{s}=\mathrm{S}_{\mathrm{r}} \mathrm{T} / \mathrm{k}$, which also is the slope of the regression line that correlates INS yield versus the soil's carbon concentration. The experimentally determined quantities $B_{r}, S_{r}$ and $s$ represent the key performance parameters of an INS system from which other parameters are derived. Using the general uncertainty estimator of a function $\mathrm{f}(\mathrm{x}, \mathrm{y}, \mathrm{z} \ldots)$ given, to a first approximation, by Equation 1 [25],

$$
\sigma_{f}^{2}=\sum_{i}\left[\sigma_{i}^{2}\left(\frac{\partial f}{\partial x}\right)_{i}^{2}\right]
$$

It is possible to derive the SD of $S_{r} T$ as $\sigma_{S}=\sqrt{ }\left(T_{\text {tot }}+B_{r} T\right)=\sqrt{ }\left(\left(S_{r}+2 B_{r}\right) T\right)$. The minimum detection limit (MDL) is defined as the number of counts above the background that differs from the background by a given confidence level; for example for a $99 \%$ confidence level the peak must contain three standard deviation counts above the background, and thus we can write:

$$
\mathrm{MDL}=3 \times \sqrt{ }\left(\mathrm{B}_{\mathrm{r}} \times \mathrm{T}\right) \text { (counts) }
$$

Further, the relative SD for a signal at the MDL level, RSDMDL, is given by $\sigma_{\mathrm{MDL}} / \mathrm{MDL}_{\mathrm{c}}$, Equation 3,

$$
\operatorname{RSDMDL}=\sqrt{ }\left[2 / 9+1 / 3 \operatorname{sqrt}\left(\mathrm{B}_{\mathrm{r}} \mathrm{T}\right)\right]
$$

The RSDMDL, plotted in Figure 5, is bound between 0.745 for $\mathrm{B}_{\mathrm{r}} \mathrm{T}=1$ and approaches asymptotically 0.471 for $\mathrm{B}_{\mathrm{r}} \mathrm{T} \rightarrow \infty, \mathrm{B}_{\mathrm{r}}$ or $\mathrm{T}$ can be changed independently.

The elemental density corresponding to the number of counts given in Equation 2 is obtained by dividing Equation 2 by s, thus,

$$
\operatorname{MDL}_{\mathrm{E}}=\left(3 \times \mathrm{k} / \mathrm{S}_{\mathrm{r}}\right) \times \sqrt{ }\left(\mathrm{B}_{\mathrm{r}} / \mathrm{T}\right) / \mathrm{s} \quad\left(\mathrm{g} \mathrm{E} / \mathrm{cm}^{2}\right)
$$

Similarly, the minimum detectable change (MDC) defined as a change of three standard deviations in the signal level error, we can write,

$$
\mathrm{MDC}=3 \times \sqrt{ }\left(\left(\mathrm{S}_{\mathrm{r}}+2 \mathrm{~B}_{\mathrm{r}}\right) \times \mathrm{T}\right)(\text { counts })
$$

and, in terms of elemental concentration, 


$$
\mathrm{MDC}_{\mathrm{E}}=\left(3 \times \mathrm{k} / \mathrm{S}_{\mathrm{r}}\right) \times \sqrt{ }\left(\left(\mathrm{S}_{\mathrm{r}}+2 \mathrm{~B}_{\mathrm{r}}\right) / \mathrm{T}\right) / \mathrm{s} \quad\left(\mathrm{g} \mathrm{E} / \mathrm{cm}^{2}\right)
$$

From Equations 4 and 6, it is apparent that increasing the counting time reduces the $\mathrm{MDL}_{\mathrm{E}}$ and the $\mathrm{MDC}_{\mathrm{E}}$. Similarly, increasing the sensitivity of $\mathrm{s}$ or $\mathrm{S}_{\mathrm{r}}$, the signal counting-rate, by increasing the number of detectors also will lower the $\mathrm{MDL}_{\mathrm{E}}$ and $\mathrm{MDC}_{\mathrm{E}}$. Finally, reducing the background counting-rate by improving the shielding of the system also will lower MDLE and $\mathrm{MDC}_{\mathrm{E}}$. These features are graphed in Figure 6.

Figure 4. Partial gamma-ray spectrum in which an energy interval "ab", located under the carbon photopeak, marks the boundary of the total counts, $\mathrm{T}_{\mathrm{t}}$, and a background counts enclosed by the trapezoid's area "abcd".

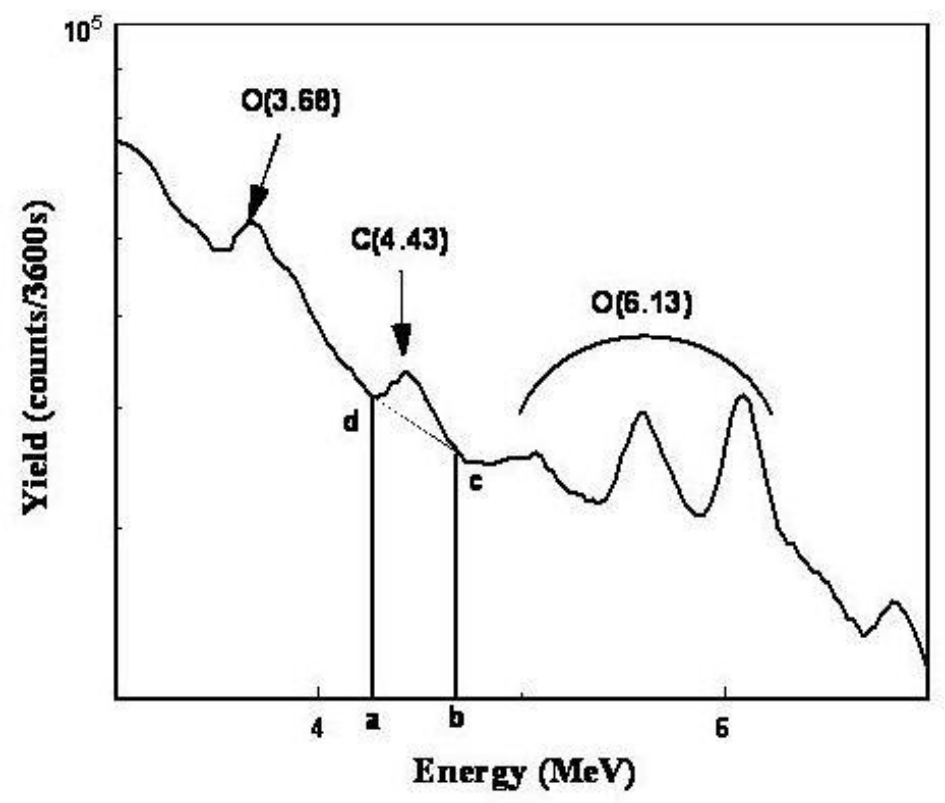

\section{Results}

Soil carbon measurements were taken over two 28-day injections episodes, in 2008 and in 2009. The soil carbon levels were measured above a HS pre- and post-injection and away from the horizontal well. No chemical analysis of soil samples were performed in order not to disturb the soil $\mathrm{CO}_{2}$ flow conditions. The net carbon yields, taken over one hour show a drop in soil carbon levels above a hot spot while simultaneously demonstrating no changes in silicon, oxygen and other elements in the background or above the HS; Table 1 shows the net counts in silicon ( $\mathrm{Si})$, oxygen $(\mathrm{O})$ and carbon peaks [15]. To plot the graphs given in Equations 2, 4, and 6 the background count-rate, $\mathrm{B}_{\mathrm{r}}$, was averaged over the two injection episodes, Table 2. The lower background in 2009 is attributed to the malfunctioning of one of the three detectors, thus reducing the background by about a third. Correcting for this anomaly in 2009, the estimated mean background rate, $\mathrm{B}_{\mathrm{r}}$, was about 50,000 counts/min, and the sensitivity, s, was approximately 1,500 counts $/ \mathrm{min} /\left(\mathrm{kg} \mathrm{C} / \mathrm{m}^{2}\right)$. Using these values the relative SD of a signal at the level of the detection limit given by Equation 3 is plotted versus time (Figure 5). Using the same values for $\mathrm{B}_{\mathrm{r}}$ and $\mathrm{s}$, the $\mathrm{MDL}_{\mathrm{E}}$ and $\mathrm{MDC}_{\mathrm{E}}$, were calculated using Equations 4 and 6 , respectively, and plotted in Figure 6. Quadrupling the number of detectors quadruples the signal and 
the background reducing the $\mathrm{MDL}_{\mathrm{E}}$ and $\mathrm{MDC}_{\mathrm{E}}$ by a factor of two. This is shown by the graph $\mathrm{MDL}_{\mathrm{E}}-4 \mathrm{Det}$ in Figure 6.

Table 1. Analyses of the $\mathrm{Si}, \mathrm{O}$, and C peaks of the INS spectra measured during the 2008 and 2009 injection periods. Measurements were taken at a hot spot (HS), and the background (B) was determined in 2008 off the horizontal well; in 2009 it was determined off the well and at a pre-injection HS.

\begin{tabular}{|c|c|c|c|c|c|c|}
\hline \multicolumn{7}{|c|}{ 2008-During Injection } \\
\hline & \multicolumn{3}{|c|}{ Hot Spot (HS) } & \multicolumn{3}{|c|}{ Background (B) } \\
\hline & $\mathrm{Si}$ & $\mathrm{O}$ & $\mathrm{C}$ & $\mathrm{Si}$ & $\mathrm{O}$ & $\mathrm{C}$ \\
\hline $\mathbf{N}$ & 8 & 8 & 7 & 12 & 12 & 11 \\
\hline Mean & $1,031,332$ & 622,914 & 47,137 & $1,008,545$ & 636,929 & 53,704 \\
\hline STD Deviations & 24,858 & 28,328 & 3,610 & 16,530 & 48,235 & 4,731 \\
\hline STD Deviations (\%) & 2.4 & 4.5 & 7.4 & 1.6 & 7.5 & 8.8 \\
\hline STD Error $(\%)$ & 0.8 & 1.6 & 2.8 & 0.5 & 2.2 & 2.7 \\
\hline$\Delta(1-\mathrm{HS} / \mathrm{B}) \times 100$ & 2.3 & -2.2 & -14.0 & --- & --- & --- \\
\hline \multicolumn{7}{|c|}{ 2009-Pre-Injection } \\
\hline & \multicolumn{3}{|c|}{ Hot Spot } & \multicolumn{3}{|c|}{ Background } \\
\hline & $\mathrm{Si}$ & $\mathrm{O}$ & $\mathrm{C}$ & $\mathrm{Si}$ & $\mathrm{O}$ & $\mathrm{C}$ \\
\hline $\mathbf{N}$ & 9 & 9 & 8 & 5 & 5 & 5 \\
\hline Mean & 787,977 & 650,746 & 79,728 & 759,986 & 665,833 & 81,228 \\
\hline STD Deviations & 15,066 & 13,714 & 4,850 & 5,860 & 5,811 & 3,916 \\
\hline STD Deviations (\%) & 1.9 & 2.1 & 6.1 & 0.8 & 0.9 & 4.8 \\
\hline STD Error $(\%)$ & 0.6 & 0.7 & 2.2 & 0.4 & 0.4 & 2.1 \\
\hline$\Delta(1-\mathrm{HS} / \mathrm{B}) \times 100$ & 3.7 & -2.3 & -1.9 & --- & --- & --- \\
\hline \multicolumn{7}{|c|}{ 2009-Post-Injection } \\
\hline & \multicolumn{3}{|c|}{ Hot Spot } & \multicolumn{3}{|c|}{ Background } \\
\hline & $\mathrm{Si}$ & $\mathrm{O}$ & $\mathrm{C}$ & $\mathrm{Si}$ & $\mathrm{O}$ & $\mathrm{C}$ \\
\hline $\mathbf{N}$ & 9 & 9 & 8 & 3 & 3 & 3 \\
\hline Mean & 842,562 & 628,521 & 78,850 & 812,448 & 635,948 & 84,718 \\
\hline STD Deviations & 19,889 & 7,117 & 6,079 & 5,751 & 8,725 & 4,566 \\
\hline STD Deviations (\%) & 2.4 & 1.1 & 7.6 & 0.7 & 1.4 & 5.4 \\
\hline STD Error $(\%)$ & 0.8 & 0.4 & 2.7 & 0.4 & 0.8 & 3.1 \\
\hline$\Delta(1-\mathrm{HS} / \mathrm{B}) \times 100$ & 3.7 & -1.2 & -6.9 & --- & --- & --- \\
\hline
\end{tabular}

Table 2. Mean background counts during 2008 and 2009, and combined over two years; $n$ is the number of measurements, SDEV is the standard deviation, and CV is the coefficient of variation $(\mathrm{SDEV} / \mathrm{sqrt}(\mathrm{n}))$.

\begin{tabular}{|c|c|c|c|}
\hline Year & 2008 & 2009 & Combined \\
\hline $\mathbf{n}$ & 20 & 27 & 47 \\
\hline Mean & $3,338,759$ & $2,102,343$ & $3,232,342$ \\
\hline SDEV (\%) & $43,119(1.29)$ & $15,384(0.73)$ & $65,455(2.03)$ \\
\hline CV (\%) & $9,642(0.29)$ & $2,961(0.14)$ & $9,548(0.30)$ \\
\hline
\end{tabular}


Figure 5. Relative standard deviation of a minimum detection limit signal (RSDMDL) based on Equation 3; it is bounded at $75 \%$, and asymptotically approaches $47.14 \%$ for long counting times.

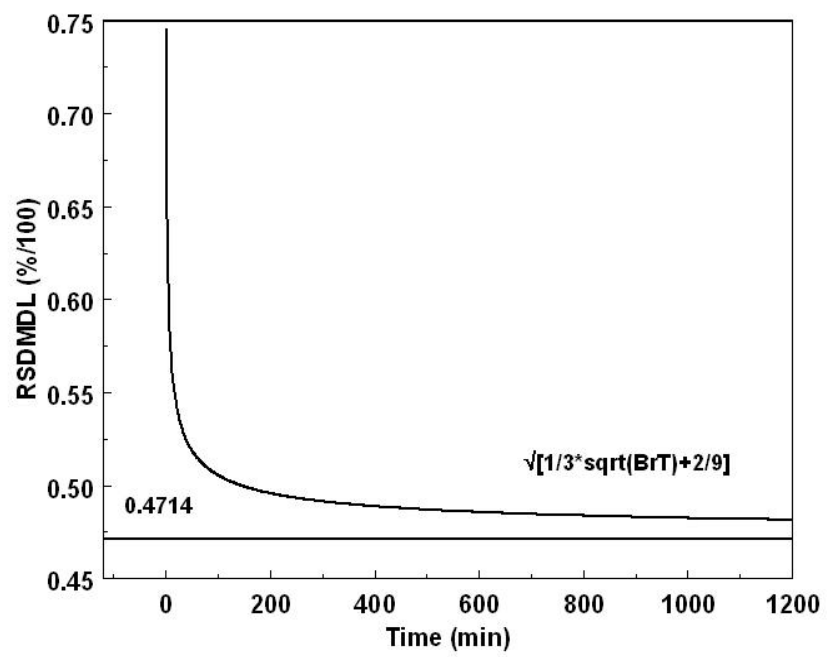

Figure 6. Minimum detection limit, MDL, and minimum detection change, MDC, respectively, based on Equations 4 and 6 versus counting time T. Increasing the sensitivity also impacts the MDC.

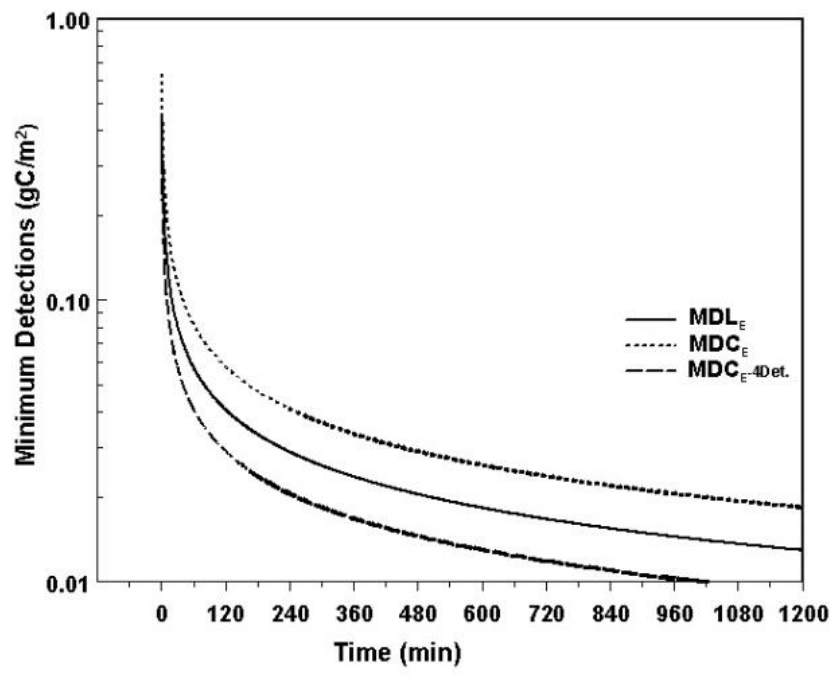

\section{Discussion}

Ideally no underground leakage of $\mathrm{CO}_{2}$ should be occurring from underground reservoirs regardless of their size. However, practically, some very low leaks in the order of $0.01 \%$ over the expected life-time of a reservoir may be acceptable. The dispersion of the leaks over the reservoir's surface area and their dilution during migration toward the surface would result in very low changes in the surface fluxes. These amounts are below the detection limits of the current instrumentation that was tuned at test facilities operating with higher fluxes. Furthermore, current instrumentation provides point measurements in time and space. At potential leak sites, this instrumentation is being used near injection- and old abandoned-wells, and possibly along known faults. The concerns with MDLs and 
with covering the entire area above the reservoir, which may amount to hundreds of square-kilometers, continually are addressed by developing new improved instrumentation. One new approach is to monitor secondary parameters that are affected by $\mathrm{CO}_{2}$ fluxes or, alternatively, combining a few modalities to improve the signal-to-noise ratio. Examples of secondary quantities include the quality of the drinking water, reflectance spectroscopy of the vegetation above-ground, and impact on the species forming the vegetation. However, noise levels and natural fluctuations continue to pose problems.

Monitoring carbon in soil, using an INS system, is yet another indirect method to detect possible leaks from deep reservoirs. The viability of INS was demonstrated by detecting a drop in the soil's carbon levels following fumigation with $\mathrm{CO}_{2}$. The uniqueness of INS approach offers time integration of a cumulative effect of a low leak that slowly influences the vegetation and near-surface $\mathrm{pH}$ levels that, in turn, alter the carbon level. The non-destructive measurements made by INS enable us to acquire sequential readings in exactly the same spot. Its sensitivity is further enhanced by the ability to measure large volumes of soil when operating in static- and scanning-modes; in principle, this enables coverage of the entire area above the reservoir, thus providing spatial averaging of the signal from the entire site. These features are well suited for monitoring possible changes in the soil carbon for potential leaks in any location. In addition, a very unique feature of INS is that we can reduce errors and lower the detection limits by extending the counting time, increasing the sensitivity of the system, or lowering the background, thus enhancing the capacity of INS to detect potential $\mathrm{CO}_{2}$ leaks.

The elemental peaks shown in Table 1 do not exhibit the same drop in 2009 as does the background in Table 2. The reason for this is not completely clear. It is speculated that, since the background radiation is more multidirectional than the specific peaks that originate in the soil, this may have to do with geometric factors depending on which detector malfunctioned, viz., the middle one or one of the side detectors. More experiments are needed to clarify this difference in response, as are others to determine the threshold values at which $\mathrm{CO}_{2}$ fluxes begin to affect the vegetation and near-surface carbon storage.

\section{Summary}

The hypothesis that leaking $\mathrm{CO}_{2}$ suppresses the near surface carbon was validated and suitability of the INS system to measure these changes in soil was demonstrated. INS is a unique addition to the arsenal of tools for monitoring geological carbon sequestration. This new approach using INS offers the possibility of temporal-spatial integration, thus enhancing the capability for detecting low-level leaks. In addition, the paper detailed how the measurement error, $\mathrm{MDL}_{\mathrm{E}}$ and $\mathrm{MDC}_{\mathrm{E}}$, can be reduced by extending the counting time and increasing the system's sensitivity. INS alone or in combination with other system will improve monitoring capabilities and enhance the success of the CCS programs. It would be highly desirable to perform controlled experiments in which soil $\mathrm{CO}_{2}$ levels are doubled and record the threshold levels impacting the vegetation and TOC. These would have to be performed with different soil types. 


\section{Acknowledgements}

Special thanks are due to L.H. Spangler, L.M., Dobeck from Montana State University at Bozeman and S. Mitra from Brookhaven National Laboratory at Upton NY, for their assistance in preparing and carrying out the experiments at the ZERT facility. Support was provided by the U.S. Department of Energy, under Contract No. DE-AC02-98CH10886.

\section{References}

1. Tans, P. Trends in Atmospheric Carbon Dioxide-Mauna Loa; US Department of Commerce/ National Oceanic and Atmospheric Administration: Boulder, CO, USA. Available online: http://www.esrl.noaa.gov/gmd/ccgg/trends/ (accessed on 9 March 2011).

2. International Energy Outlook 2007; Energy Information Administration, US Department of Energy (EIA): Washington, DC, USA, May 2007. Available online: http://www.eia.doe.gov/ oiaf/ieo/ (accessed on 9 March 2011). .

3. Socolow, R.; Hotinski, R.; Greenblatt, J.B.; Pacala, P. Solving the climate problemTechnologies available to curb $\mathrm{CO}_{2}$ emissions. Environment 2004, 46, 8-19.

4. Greenblatt, J.B.; Sarmiento, J.L. Variability and climate feedback mechanisms in ocean uptake of $\mathrm{CO}_{2}$. In The Global Carbon Cycle: Integrating Humans, Climate, and the Natural World; Field, C.B., Raupach, M.R., Eds.; Island Press: Washington, DC, USA, 2004.

5. Carbon Sequestration Technology Roadmap and Program Plan; United States Department of Energy/Office of Fossil Energy/National Energy Technology Laboratory (USDOE/FE/NETL): Pittsburgh, PA, USA, 2007. Available online: http://www.netl.doe.gov (accessed on 9 March 2011).

6. Using the Class V Experimental Technology Well Classification for Pilot GS Projects; UIC Program Guidance (UICPG \#83); Environmental Protection Agency (EPA): Washington, DC, USA, 2007.

7. Core Energy, LLC Class V UIC Injection Permit; Permit No. MI-137-5X25-0001; Environmental Protection Agency (EPA): Washington, DC, USA, draft version issued July 2008.

8. Underground Injection Control Program (UIC); Environmental Protection Agency (EPA): Washington, DC, USA, 12 February 2008. Available online: http://www.epa.gov/safewater/ uic/index.html (accessed on 8 June 2008).

9. Geologic Sequestration of Carbon Dioxide; Environmental Protection Agency (EPA): Washington, DC, USA, 2008. Available online: http://www.epa.gov/safewater/uic/ wells_sequestration.html (accessed on 9 March 2011).

10. International Panel on Climate Change (IPCC). IPCC Special Report on Carbon Doxide Capture and Storage; Metz, B., Davidson, O., de Coninck, H., Loos, M., Meyer, L., Eds.; Cambridge University Press: Cambridge, UK, 2005; p. 195.

11. Best Practices for: Monitoring, Verification, and Accounting of $\mathrm{CO}_{2}$ Stored in Deep Geologic Formation; DOE/NETL-311/081508; United States Department of Energy/Office of Fossil Energy/National Energy Technology Laboratory (USDOE/FE/NETL): Pittsburgh, PA, USA, 2009. 
12. Lewicki, J.L.; Hilley, G.E.; Laura Dobeck, L.; Spangler, L. Dynamics of $\mathrm{CO}_{2}$ fluxes and concentrations during a shallow subsurface $\mathrm{CO}_{2}$ release. Environ. Earth Sci. 2010, 60, 285-297.

13. Saripalli, P.; Amonette, J.; Rutz, F.; Gupta, N. Deign of sensor networks for long term monitoring of geological sequestration. Energy Convers. Manage. 2006, 47, 1968-1974.

14. West, J.M.; Pearce, J.M.; Coombs, P.; Ford, J.R.; Scheib, C.; Colls, J.J.; Smith, K.L.; Steven, M.D. The impact of controlled injection of $\mathrm{CO}_{2}$ on the soil ecosystem and chemistry of an English lowland pasture. Energy Procedia 2009, 1, 1863-1870.

15. Wielopolski, L.; Mitra, S. Near-surface soil carbon detection for monitoring $\mathrm{CO}_{2}$ seepage from a geological reservoir. Environ. Earth Sci. 2010, 60, 307-312.

16. Anderson, D.E.; Farrar, C.D. Eddy covariance measurement of $\mathrm{CO}_{2}$ flux to the atmosphere from the area of high volcanogenic emissions, Mammoth Mountain, California. Chem. Geol. 2001, 177, $31-42$.

17. Annunziatellis, A.; Beaubien, S.E.; Bigi, S.E.; Ciotoli, S.; Coltella, G.; Lombardi, M. Gas migration along fault systems and through the vadose zone in the Latera caldera (central Italy) implications for $\mathrm{CO}_{2}$ geological storage. Int. J. Greenh. Gas Control 2008, 2, 253-372.

18. Spangler, L.H.; Dobeck, L.M.; Repasky, K.S.; Nehrir, A.; Humphries, S.; Barr, J.; Keith, C.; Shaw, J.; Rouse, J.; Cunningham, A.; et al. A controlled field pilot for testing near surface $\mathrm{CO}_{2}$ detection techniques and transport models. Energy Procedia 2009, 1, 2143-2150.

19. Spangler, L.H.; Dobeck, L.M.; Repasky, K.S.; Nehrir, A.R.; Humphries, S.D.; Barr, J.L.; Keith, C.J.; Shaw, J.A.; Rouse, J.H.; Cunningham, A.B.; et al. A shallow subsurface controlled release facility in Bozeman, Montana, USA, for testing near surface $\mathrm{CO}_{2}$ detection techniques and transport models. Environ. Earth Sci. 2010, 60, 227-239.

20. Wielopolski, L.; Hendrey, G.; Johnsen, K.; Mitra, S.; Prior, S.A.; Rogers, H.H.; Torber, H.A. Nondestructive system for analyzing carbon in the soil. Soil Sci. Soc. Am. J. 2008, 72, 1269-1277.

21. Wielopolski, L.; Mitra, S.; Hendrey, G.; Orion, I.; Prior, S.; Rogers, H.; Runion, B.; Torbert, A. Non-destructive Soil Carbon Analyzer (ND-SCA); BNL Report No.72200-2004; Brookhaven National Lab: Upton, NY, USA, 2004.

22. Wielopolski, L.; Johnston, K.; Zhang, Y. Comparison of soil analysis methods based on samples withdrawn from different volumes: Correlations versus Calibrations. Soil Sci. Soc. Am. J. 2010, $74,812-819$.

23. Wielopolski, L.; Chatterjee, A.; Mitra, S.; Lal, R. In Situ Determination of Soil Carbon Pool by Inelastic Neutron Scattering: Comparison with Dry Combustion. Geoderma 2010, 160, 394-399.

24. Evans, R.D. The Atomic Nucleus; McGraw-Hill Book Company: New York, NY, USA, 1955; p. 746.

25. Bevington, F.P.; Robinson, D.K. Data Reduction and Error Analysis for the Physical Sciences; McGraw-Hill Book Company: New York, NY, USA, 1969; p. 56.

(C) 2011 by the authors; licensee MDPI, Basel, Switzerland. This article is an open access article distributed under the terms and conditions of the Creative Commons Attribution license (http://creativecommons.org/licenses/by/3.0/). 